\title{
Evoked magnetic fields from primary and secondary somatosensory cortices: A reliable tool for assessment of cortical processing in the neonatal period
}

\author{
Citation for published version (APA):
}

Nevalainen, P., Pihko, E., Metsaranta, M., Sambeth, A., Wikstrom, H., Okada, Y., Autti, T., \& Lauronen, L. (2012). Evoked magnetic fields from primary and secondary somatosensory cortices: A reliable tool for assessment of cortical processing in the neonatal period. Clinical Neurophysiology, 123(12), 2377-2383. https://doi.org/10.1016/j.clinph.2012.05.021

Document status and date:

Published: 01/12/2012

DOI:

10.1016/j.clinph.2012.05.021

Document Version:

Publisher's PDF, also known as Version of record

\section{Document license:}

Taverne

\section{Please check the document version of this publication:}

- A submitted manuscript is the version of the article upon submission and before peer-review. There can be important differences between the submitted version and the official published version of record. People interested in the research are advised to contact the author for the final version of the publication, or visit the DOI to the publisher's website.

- The final author version and the galley proof are versions of the publication after peer review.

- The final published version features the final layout of the paper including the volume, issue and page numbers.

Link to publication

\footnotetext{
General rights rights.

- You may freely distribute the URL identifying the publication in the public portal. please follow below link for the End User Agreement:

www.umlib.nl/taverne-license

Take down policy

If you believe that this document breaches copyright please contact us at:

repository@maastrichtuniversity.nl

providing details and we will investigate your claim.
}

Copyright and moral rights for the publications made accessible in the public portal are retained by the authors and/or other copyright owners and it is a condition of accessing publications that users recognise and abide by the legal requirements associated with these

- Users may download and print one copy of any publication from the public portal for the purpose of private study or research.

- You may not further distribute the material or use it for any profit-making activity or commercial gain

If the publication is distributed under the terms of Article 25fa of the Dutch Copyright Act, indicated by the "Taverne" license above, 


\title{
Evoked magnetic fields from primary and secondary somatosensory cortices: A reliable tool for assessment of cortical processing in the neonatal period
}

\author{
Päivi Nevalainen ${ }^{\mathrm{a}, \mathrm{b}, *}$, Elina Pihko ${ }^{\mathrm{c}}$, Marjo Metsäranta ${ }^{\mathrm{d}}$, Anke Sambeth ${ }^{\mathrm{a}, \mathrm{e}}$, Heidi Wikström ${ }^{\mathrm{f}}$, \\ Yoshio Okada ${ }^{\mathrm{g}}$, Taina Autti ${ }^{\mathrm{h}}$, Leena Lauronen ${ }^{\mathrm{a}, \mathrm{i}}$ \\ a BioMag Laboratory, Hospital District of Helsinki and Uusimaa, HUSLAB, Helsinki University Central Hospital (HUCH), Helsinki, Finland \\ ${ }^{\mathrm{b}}$ Department of Clinical Neurophysiology, Jorvi Hospital, Espoo, Finland \\ ${ }^{\mathrm{c}}$ Brain Research Unit, Low Temperature Laboratory, Aalto University School of Science, Espoo, Finland \\ ${ }^{\mathrm{d}}$ Department of Pediatrics, HUCH, Helsinki, Finland \\ e Faculty of Psychology and Neuroscience, Department of Neuropsychology and Psychopharmacology, Maastricht University, Maastricht, The Netherlands \\ ${ }_{\mathrm{f}}$ Department of Gastrointestinal Surgery, HUCH, Helsinki, Finland \\ ${ }^{\mathrm{g}}$ Department of Neurology, Children's Hospital Boston, Harvard Medical School, Boston, MA, USA \\ ${ }^{\mathrm{h}}$ Helsinki Medical Imaging Center, HUCH, Helsinki, Finland \\ ${ }^{\mathrm{i}}$ Department of Clinical Neurophysiology, Hospital for Children and Adolescents (HUCH), and Helsinki University, Helsinki, Finland
}

\section{A R T I C L E I N F O}

Article history:

Accepted 24 May 2012

Available online 29 June 2012

\section{Keywords:}

Magnetoencephalography

Somatosensory system

Neonate

Primary somatosensory cortex

Secondary somatosensory cortex

Somatosensory evoked field (SEF)

\section{H I G H L I G H T S}

- In 46 healthy newborns, activity from both the primary (SI) and secondary somatosensory cortices (SII) was detectable with magnetoencephalography to tactile stimulation of the contralateral index finger during quiet sleep (QS).

- No significant interhemispheric differences in the responses from SI or SII existed.

- Within the neonatal period [postmenstrual age (PMA) between 37 and 44 weeks] PMA, height, or gender did not significantly affect the latency or strength of the somatosensory evoked magnetic fields (SEFs).

\begin{abstract}
A B S T R A C T
Objective: To determine interhemispheric differences and effect of postmenstrual age (PMA), height, and gender on somatosensory evoked magnetic fields (SEFs) from the primary (SI) and secondary (SII) somatosensory cortices in healthy newborns.

Methods: We recorded SEFs to stimulation of the contralateral index finger (right in 46 and left in 12) healthy fullterm newborns and analyzed the magnetic responses with equivalent current dipoles.

Results: Activity from both the SI and SII was consistently detectable in the contralateral hemisphere of the newborns during quiet sleep. No significant interhemispheric differences existed in SI or SII response peak latencies, source strengths, or location ( $n=8$, quiet sleep). SI or SII response peak latency or source strength were not significantly affected by PMA, height, or gender.

Conclusions: During the neonatal period (PMA 37-44 weeks), activity from the contralateral SI and SII can be reliably evaluated with MEG. The somatosensory responses are similar in the left and right hemispheres and no corrections for exact PMA, height, or gender are necessary for interpreting the results. However, the evaluation should be conducted in quiet sleep.

Significance: The reproducibility of the magnetic SI and SII responses suggests clinical applicability of the presented MEG method.

(c) 2012 International Federation of Clinical Neurophysiology. Published by Elsevier Ireland Ltd. All rights reserved.
\end{abstract}

\footnotetext{
* Corresponding author at: BioMag Laboratory, Hospital District of Helsinki and Uusimaa, HUSLAB, HUCH, P.O. Box 340, FI-00029 HUS, Helsinki, Finland. Tel.: +358 9 47172092; fax: +358 947175781.

E-mail address: paivi.nevalainen@helsinki.fi (P. Nevalainen).
}

\section{Introduction}

In current neonatal medicine, improving the neurological outcome of increasing numbers of very preterm infant survivors remains a major challenge. At present, brain pathology in at risk infants or after insults is routinely evaluated by means of structural 
neuroimaging, including cranial ultrasound and conventional MRI, both having incontrovertible prognostic significance (Woodward et al., 2006; Mathur et al., 2010). However, combining structural neuroimaging with methods assessing functional integrity could provide not only new insights into the mechanisms of brain pathology, but also powerful, clinically applicable tools to further delineate prognostic evaluations in at risk infants or after early brain insults (Majnemer and Rosenblatt, 1996; Vanhatalo et al., 2009; Trollmann et al., 2010).

The intactness of the somatosensory pathways from the periphery to the primary somatosensory cortex (SI) is reflected in the somatosensory evoked potentials (SEPs), which are also applicable in infants (Hrbek et al., 1973; Desmedt et al., 1976; Willis et al., 1984; Zhu et al., 1987; Laureau et al., 1988; George and Taylor, 1991; Trollmann et al., 2010). The earliest cortical SEPs are, however, of limited value in evaluating higher level cortical processing. In recent years, several groups have employed new tools such as functional magnetic resonance imaging (fMRI) (Erberich et al., 2006; Heep et al., 2009; Arichi et al., 2010) and magnetoencephalography (MEG) (Pihko et al., 2004, 2005; Lauronen et al., 2006; Nevalainen et al., 2008a,b; Pihko et al., 2009, 2011) as well as novel EEG techniques (Vanhatalo et al., 2009) in studies on cortical somatosensory processing in newborns.

Similar to electroencephalography (EEG), MEG provides a temporal resolution of millisecond scale. Additionally, MEG's spatial accuracy is reasonable also in newborns (Pihko et al., 2011) enabling, e.g. separation of activity from the primary (SI) and secondary somatosensory cortices (SII) (Nevalainen et al., 2008a; Pihko et al., 2011). SI and SII activation is indeed consistently seen after tactile stimulation of the index finger in newborns, but there are marked differences in the activity patterns of these areas as compared with adults (Lauronen et al., 2006; Nevalainen et al., 2008a). In adults, the initial SI response, N20m, is quickly followed by a $\mathrm{P} 30 \mathrm{~m} / \mathrm{P} 35 \mathrm{~m}$ at a similar location but opposite (posterior) source current orientation. In newborns the shift in current orientation is not seen but instead a prolonged anteriorly pointing current source underlies the response during the first $100 \mathrm{~ms}$ (Lauronen et al., 2006). Over the first 2-3 years of life, the SI response gradually develops from the neonatal form to an adult-like multipeak pattern (Pihko et al., 2009). In addition, in newborns the SII activity is strong during quiet sleep (QS) (Nevalainen et al., 2008a), whereas in adults SII responses diminish during sleep (Kitamura et al., 1996; Kakigi et al., 2003). Similar to adults, the SII activity in newborns is also significantly weakened by shortening the interstimulus interval (Nevalainen et al., 2008a). In some newborns, ipsilateral responses, mostly arising from SII but also from SI are detectable during QS (Nevalainen et al., 2008a).

This study aimed at characterizing the normal variation in the newborn SEFs in a relatively large subject group for future patient studies. To maximize the power of SEFs as a clinical measure in the newborn period, determining the effects of exact developmental state [postmenstrual age (PMA)], body size (height), and gender is essential. In addition, the previous studies have mainly concentrated on recording SEFs from the right hemisphere and no interhemispheric comparisons are presently available. This study was undertaken to evaluate these issues.

\section{Methods}

\subsection{Participants}

The study group comprised of 46 healthy fullterm newborns (19 females, 27 males), recruited from the maternity ward of the Helsinki University Central Hospital during years 2002-2008. The parents gave their written informed consent. The Ethics Committee for Pediatrics, Adolescent medicine, and Psychiatry, Hospital District of Helsinki and Uusimaa, approved the study protocol. Data of $44 / 46$ of the newborns has been used for other purposes in one or several previous publications (Pihko et al., 2004; Lauronen et al., 2006; Nevalainen et al., 2008a,b; Pihko et al., 2009, 2011). The newborns' gestational age (GA) ranged from 37 to 42 weeks (mean 40 weeks, SD 1 week 2 days; data missing from 3 newborns). We recorded the SEFs 1-6 days after birth in all but five newborns, in whom the recording took place 15-23 days after birth. Consequently, at the time of the MEG recording the postmenstrual ages (PMA i.e. gestational age + chronological age) ranged between 37 weeks 6 days and 43 weeks 1 day (mean 40 weeks 4 days, SD 1 week 2 days). The 1 -min Apgar score was $\geqslant 8$ in all but five newborns of whom one had score 5 , one had score 6 , and three had score 7 , with 5 -min follow-up scores $\geqslant 8$ in four and 7 in one. The mean birth weight was 3620 (SD 420; range 2622-4578) g, head circumference 35 (SD 1, range 33-37) $\mathrm{cm}$, and body length 51 (SD 2, range 46-56) $\mathrm{cm}$. The weight, height, and head circumference were appropriate for gestational age in all newborns. Compared with the females, the males were slightly heavier [males 3730 (440) g vs. females 3470 (350) g; Student's $t$-test for independent samples with equal variances: $t(44)=-2.13: p=0.04$ ] and taller [males $51(2) \mathrm{cm}$ vs. females 50 (2) $\mathrm{cm} ; t(44)=-2.66: p=0.01)]$. No gender difference existed in head circumference.

\subsection{Procedure}

MEG was recorded in the magnetically shielded room (Euroshield Ltd., Finland) of the BioMag Laboratory of the Helsinki University Central Hospital (HUCH) with a helmet-shaped MEG sensor array consisting of 306 independent channels: 204 planar gradiometers and 102 magnetometers (Elekta Neuromag ${ }^{\circledR}$, Elekta Oy, Helsinki, Finland). Simultaneous EEG, from one to three silver-silver-chloride disposable electrodes placed at F4, P4, Cz, or P3, and electro-oculogram (EOG), from two electrodes placed above the left and below the right eye canthi, were recorded for sleep stage monitoring. The reference electrode was on the left mastoid and the ground electrode on the forehead. The bandpass for EEG and MEG was $0.03-257 \mathrm{~Hz}$ and the sampling rate 987 or $1002 \mathrm{~Hz}$.

Before the measurement, we attached the EEG and EOG electrodes on the scalp and additionally four position indicator coils on a cloth cap. We then determined the coil positions, relative to anatomical landmarks, with a three-dimensional digitizer (Polhemus) to construct an individual Cartesian coordinate system. In this coordinate system the preauricular points determined the $x$ axis, which pointed towards the right ear. The $y$-axis was perpendicular to the $x$-axis pointing towards the nasion, and the $z$-axis, perpendicular to the $x$ - $y$-plane, pointed upwards. In the beginning of each recording set, we determined the head position inside the sensor array by feeding the position indicator coils with excitation currents to find their positions by modeling them as magnetic dipoles. The head position measurement was repeated at least twice for each recording set and the location of the head coordinate system origin with respect to the device coordinate system was expected to be stable between two consecutive head position measurements for reliability.

When necessary, the newborn was fed before placing him/her on a bed next to the MEG measuring helmet. The MEG device was in the supine position, and the newborns lay with one hemisphere downwards over the occipital part of the adult-size helmet. The tactile stimuli were taps to the tip of the index finger, contralateral to the recorded hemisphere, delivered with a diaphragm driven by an air pressure pulse (Somatosensory Stimulus Generator, 4-D NeuroImaging Inc., San Diego, USA). The stimulation and recording started when the newborn naturally fell asleep and was lying still. No sedation was used. One or two researchers were 
in the measurement room with the newborns in order to hold the stimulator on the index finger and observe the newborns' behavior. The researcher(s) coded the newborns' behavior (whether the eyes were open or closed and the presumed sleep stage) onto trigger channels linked to the raw data file. This behavioral coding, together with EEG and EOG, served for off-line sleep stage determination. In addition, the researchers observed the newborns' movements. In general, the sleeping newborns lay very still, but when occasional twitches occurred and the head moved, we interrupted the MEG recording and repeated the head position measurement. The complete session with each newborn lasted approximately $2 \mathrm{~h}$.

All 46 newborns underwent recordings from the right hemisphere with stimulation of the left index finger. Of them we obtained data in quiet sleep (QS) in 42 newborns and in active sleep (AS) in 32 newborns. In addition, we obtained recordings from the left hemisphere with stimulation of the right index finger in 12 newborns ( 11 in QS and 6 in AS).

\subsection{Data analysis}

To remove possible magnetic artifacts, we begun the data analysis by preprocessing the data with a Spatiotemporal Signal Space Separation (tSSS) method (Taulu and Simola, 2006) of the MaxFilter $^{\text {TM }}$ software (Elekta Neuromag, Helsinki, Finland) using an 8-s time window, thereby also suppressing frequencies below $0.125 \mathrm{~Hz}$. The correlation limit for tSSS was 0.9 (Medvedovsky et al., 2009). After tSSS, we manually discarded periods with movement artifacts from the data before averaging it according to the sleep stage. We characterized the sleep stages as quiet (QS) or active sleep (AS) (Prechtl, 1974) using EEG, MEG, EOG, and behavioral coding. In quiet sleep (QS) the infant had his/her eyes closed and a regular respiration pattern. EEG showed high voltage low frequency activity or tracé alternant and there were no rapid eye movements in EOG. In active sleep (AS) the infant had his/her eyes closed and an irregular respiration pattern. EEG showed low voltage high frequency activity and rapid eye movements were depicted by EOG. We discarded periods with unreliable sleep staging from further analyses (for more details see e.g. Pihko et al., 2004). The mean number of epochs in each averaged file was 265 (85). Before ECD modeling, we baseline corrected (-100 to $0 \mathrm{~ms}$ ) and lowpass filtered (at $90 \mathrm{~Hz}$ ) the averaged signals.

We then estimated the location, strength, and orientation of the neural sources by calculating equivalent current dipoles (ECDs) for SI (M60) and SII (M200) (Nevalainen et al., 2008a) in a spherical conductor model. We first visually identified the response peaks on the channel waveforms and observed the magnetic contours to ensure a dipolar field pattern coincided with the peaks. We then modeled ECDs, from an individually selected subset of MEG channels (approximately 20 channel triplets including all channels that showed a clear signal deviating from the baseline), with 1-ms intervals around the visually determined peaks. Of those ECDs with a dipolar field pattern and a goodness-of-fit (GOF) over 70\%, we selected the ECD with the greatest dipole moment for further analysis [mean GOF of the selected dipoles was $90 \%(7 \%)$ ]. In some cases the source activity seemed to persist for a longer period of time, however, and the waveforms showed no clear single peak but a platform after the initial rise. In such cases the beginning of the strongest activity was identified from the waveforms and the dipole marking the beginning of the strongest activity was chosen for further analyses. Finally, we inserted the ECDs for SI and SII into a time-varying multidipole model where the ECD locations and orientations were fixed but source strengths were allowed to change as a function of time in order to study the overall explanation by the selected ECDs for data from all sensors. When there was no peak on the channel waveforms, the magnetic contour maps showed no dipolar field pattern, and/or the ECD could not be modeled with the required GOF, the response was considered to be absent.

\subsection{Magnetic resonance imaging (MRI)}

Twelve newborns underwent MRI with a 1.5-Tesla scanner (Philips Medical Systems Achieva). In those 12 newborns, the MRI findings were within normal limits. We used the T1-weighted images for MEG-MRI integration and figures.

\subsection{Statistics}

For correlations of PMA, body length, and gender with the SEF parameters we applied multiple regression. Before testing, the independent variables PMA and body length were centered according to their mean, and the genders were assigned weights $-1 / 2$ (male) and $+1 / 2$ (female). In case the normality assumption was violated (Komogorov-Smirnov Normality test), we used Spearman's rho for correlations. For interhemispheric comparisons in those newborns with recordings from both hemispheres we applied Student's paired two-tailed $t$-tests or, when the normality assumption was violated, the Wilcoxon Signed Ranks test. We also checked the data for outliers and excluded values $>3$ SD from statistical analyses. In the comparisons of source strengths, when a response was absent we considered the strength to be $0 \mathrm{nAm}$. For level of statistical significance we chose $p<0.05$.

\section{Results}

Fig. 1 presents the grand average source waveforms as well as an example of typical individual source waveforms, magnetic field patterns, and source locations for the two prominent neonatal responses: M60 from SI and M200 from SII. In QS, the contralateral M60 response was identifiable in all newborns [mean peak latency: right hemisphere 67 (12) ms, $n=42$; left hemisphere 67 (8) ms, $n=11$ ]. Comparably, the M200 was present in 38/42 newborns in the right [mean peak latency 218 (36) ms] and $11 / 11$ in the left hemisphere [226 (31) ms]. M60 and M200 explained the data well during the first $300 \mathrm{~ms}$ in the multidipole model (Figs. 1 and 2). Ten newborns underwent recordings of both hemispheres in QS and in all of them the M60 and M200 responses were present in both hemispheres. In two of these newborns, the head position measurement for the left hemisphere was unreliable and we thus excluded these two newborns from statistical interhemispheric comparisons. In the remaining eight newborns, no significant differences existed between the hemispheres in peak latency, source strength, or absolute value of the location coordinates. Table 1 presents the mean (SD) interhemispheric differences for peak latencies, source strengths, and location coordinates. Fig. 2 displays SI and SII source waveforms from both hemispheres in four newborns.

In active sleep (AS), the M60 was present in the right hemisphere of 30/32 newborns [mean peak latency: 64 (11) ms] and the left hemisphere of 6/6 newborns [63 (9) ms]. On the contrary, the M200 in AS was identifiable in $50 \%$ of the newborns only [16/ 32 right hemispheres: 265 (82) ms; 3/6 left hemispheres: 216 (43) $\mathrm{ms}]$. In AS, only four newborns underwent recordings from both hemispheres and the interhemispheric differences were therefore not assessed.

As we found no interhemispheric differences we only used SEFs from the right hemisphere (details in Table 2) in the correlations with gender, PMA, and height. The multiple regression models including gender, PMA, and height as independent variables and peak latency or strength (of M60/M200 in AS/QS) as the dependent variable revealed no significant correlations (Fig. 3). As there was a tendency towards females having stronger M60 responses than 

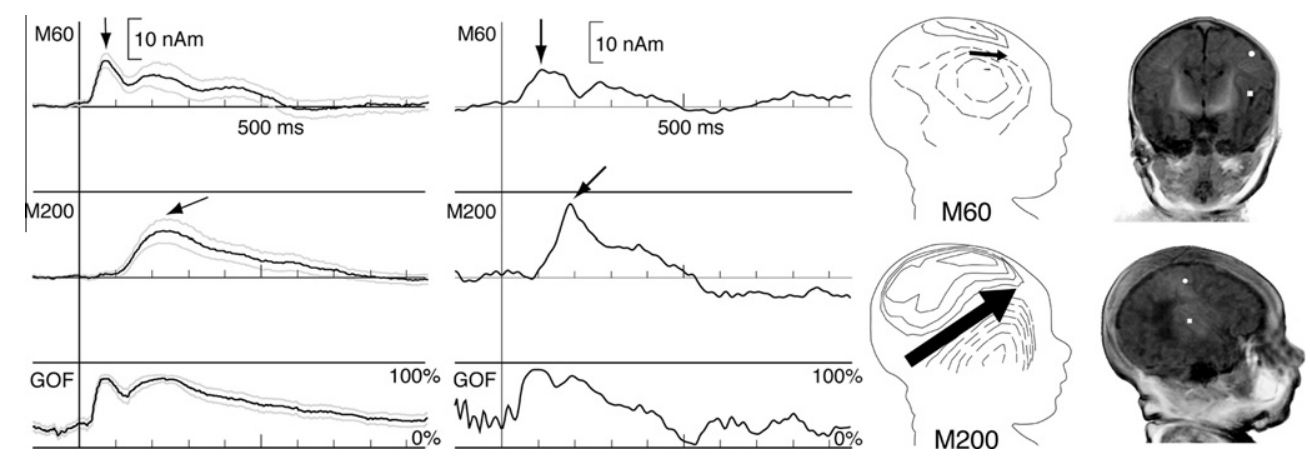

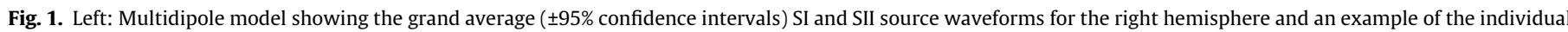

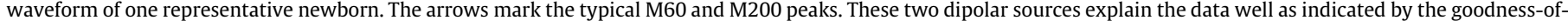

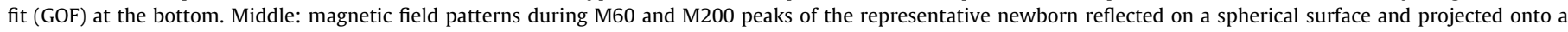

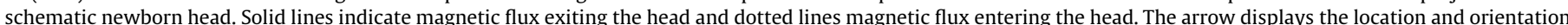

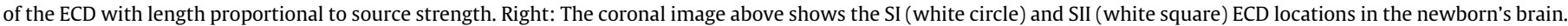
The sagittal brain slice below is on the level of the SI and SII ECDs (rendered with Voxlab; Seppä, 2011).
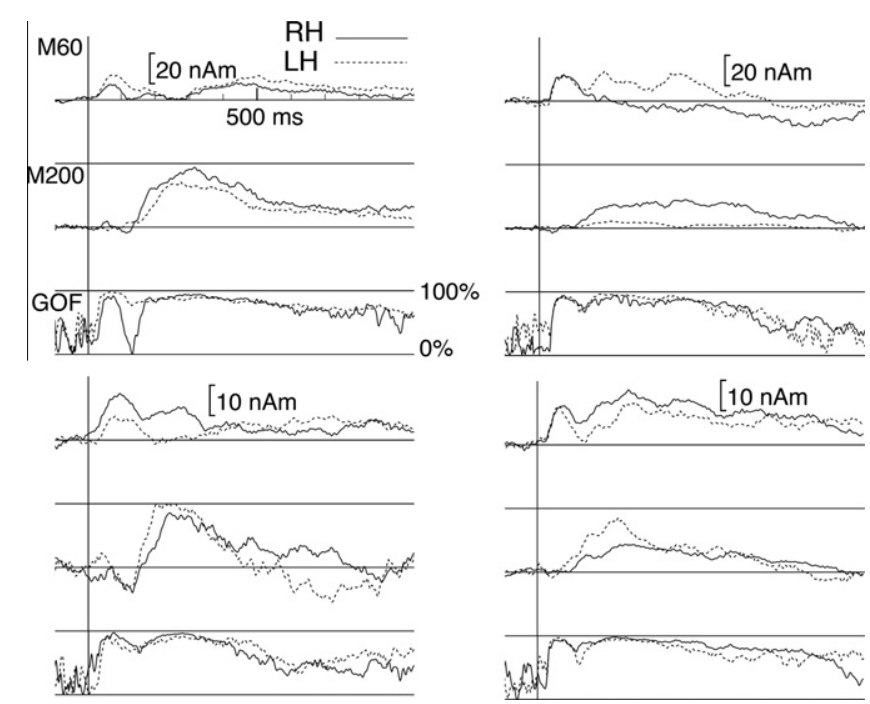

Fig. 2. Multidipole models showing source strengths and goodness-of-fit for the right and left hemisphere in four newborns in QS. The time scale is -100 to $1000 \mathrm{~ms}$. The two ECDs explain the data well as indicated by the goodness-of-fit (GOF). Note also the similar peak latencies of M60 and M200 in the two hemispheres within individuals. ( $\mathrm{RH}=$ Right hemisphere, $\mathrm{LH}=$ Left hemisphere).

males (Fig. 4), we further tested this possibility with independent samples $t$-tests, but found no significant effects (QS $p=0.06$; AS $p=0.09$ ).

\section{Discussion}

This study characterized the normal variation of SI and SII responses as well as interhemispheric differences and effects of gen-
Table 2

Number of newborns ( $n$ ) with M60 and M200 responses from the right hemisphere in quiet and active sleep, together with mean (SD) peak latencies, ECD strengths, location coordinates $(x, y, z)$, and goodness-of-fit (GOF) values.

\begin{tabular}{lrrrrr}
\hline & \multicolumn{2}{c}{ Quiet sleep } & & \multicolumn{2}{l}{ Active sleep } \\
\cline { 2 - 3 } & \multicolumn{1}{c}{ M60 } & \multicolumn{1}{c}{ M200 } & & M60 & \multicolumn{1}{c}{ M200 } \\
\hline$n$ & 42 & 38 & & 30 & 16 \\
Latency [ms] & $66(12)$ & $218(36)$ & & $64(11)$ & $265(82)$ \\
Strength [nAm] & $12(6)$ & $10(8)$ & & $10(7)$ & $4(6)$ \\
$x[\mathrm{~mm}]$ & $21(7)$ & $31(7)$ & & $21(7)$ & $32(7)$ \\
$y[\mathrm{~mm}]$ & $4(10)$ & $1(9)$ & & $5(12)$ & $0(9)$ \\
$z[\mathrm{~mm}]$ & $61(9)$ & $41(10)$ & & $60(8)$ & $41(11)$ \\
GOF $[\%]$ & $90(7)$ & $91(7)$ & & $93(4)$ & $88(7)$ \\
\hline
\end{tabular}

der, postmenstrual age, and height on contralateral SEFs in healthy fullterm newborns. In this relatively large group of 46 newborns M60 from the primary and M200 from secondary somatosensory cortex were consistently present after tactile stimulation of the index finger, particularly in quiet sleep. PMA, height, or gender had no significant effects on M60 or M200 peak latencies or strengths within the fullterm neonatal period. In all the eight newborns with successful recordings from both hemispheres in QS, both M60 and M200 responses were present in both hemispheres, and there were no significant interhemispheric differences in any of the SEF parameters.

At present SEP techniques used in clinical neurophysiology allow evaluation of the earliest cortical responses. The N1 of median nerve SEPs (Klimach and Cooke, 1988; Willis et al., 1989; Majnemer et al., 1990; Pierrat et al., 1996, 1997; Smit et al., 2000; Trollmann et al., 2010) and P1 of tibial nerve SEPs (White and Cooke, 1994; Pierrat et al., 1997; Pike and Marlow, 2000) do indeed possess predictive value in evaluating neurodevelopmental outcome in at risk infants (e.g. preterm infants), though the specificity, sen-

Table 1

Interhemispheric comparisons.

\begin{tabular}{|c|c|c|c|c|c|c|}
\hline & \multicolumn{2}{|c|}{ Right hemisphere } & \multicolumn{2}{|c|}{ Left hemisphere } & \multicolumn{2}{|c|}{ Interhemispheric difference } \\
\hline & M60 & M200 & M60 & M200 & M60 & M200 \\
\hline Latency [ms] & $68(9)$ & $229(41)$ & $69(8)$ & $229(35)$ & $8(4)$ & $36(22)$ \\
\hline $\mathrm{Q}[\mathrm{nAm}]$ & $11(4)$ & $21(15)$ & $13(6)$ & $12(10)$ & $4(3)$ & $12(14)$ \\
\hline$x[\mathrm{~mm}]$ & $22(5)$ & $29(7)$ & $-22(8)$ & $-32(9)$ & $7(6)$ & $7(6)$ \\
\hline$y[\mathrm{~mm}]$ & $1(11)$ & $-4(11)$ & $3(8)$ & $2(10)$ & $8(7)$ & $12(8)$ \\
\hline$z[\mathrm{~mm}]$ & $61(8)$ & $42(9)$ & $62(8)$ & $48(9)$ & $8(3)$ & $8(6)$ \\
\hline
\end{tabular}

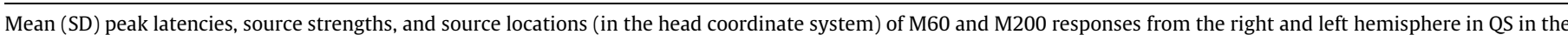

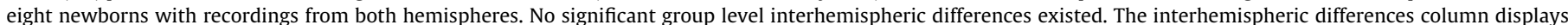
mean (SD) of absolute individual interhemispheric differences. 

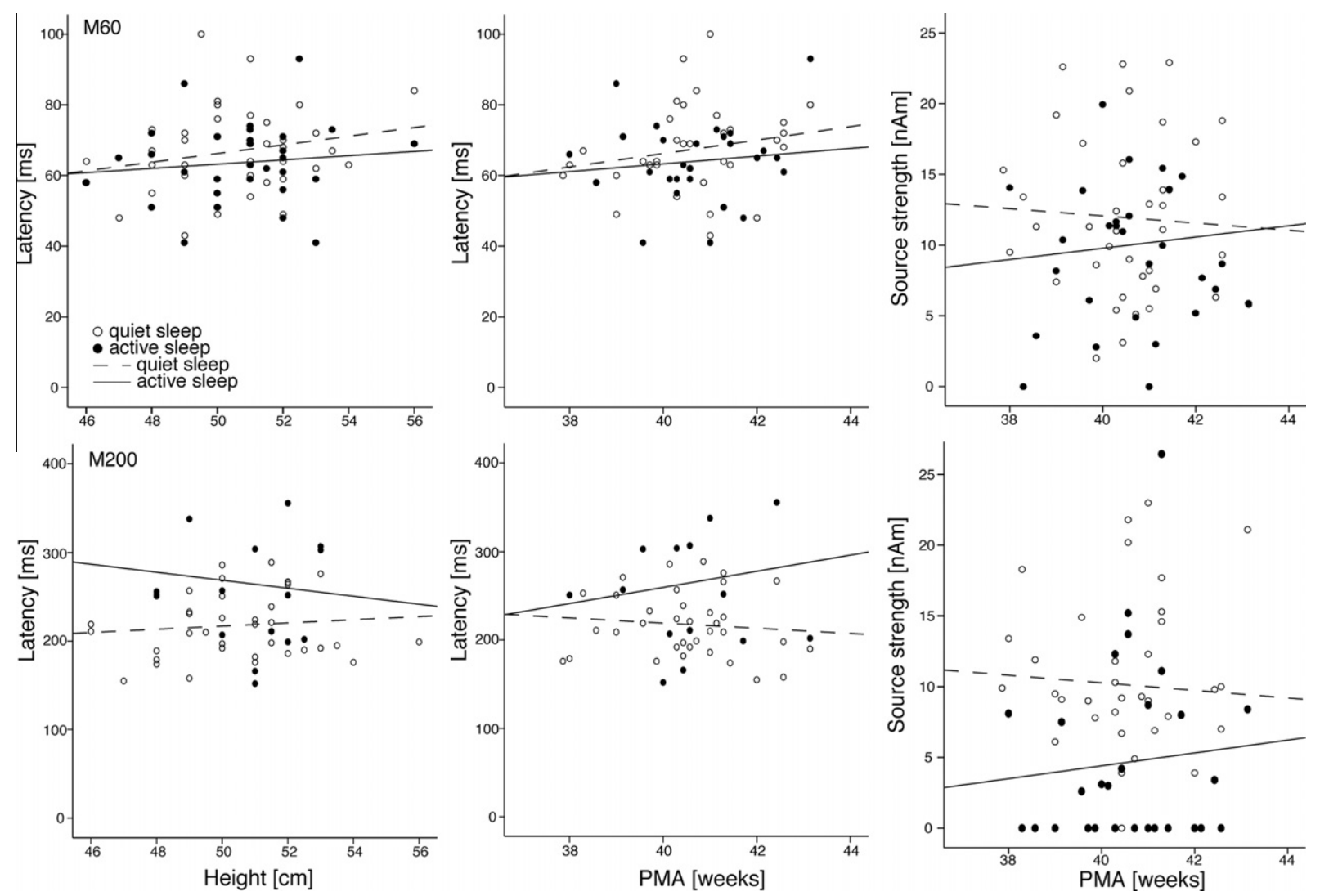

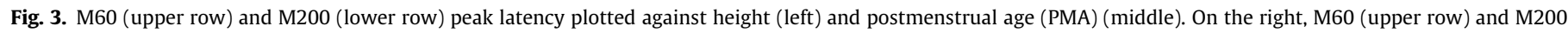

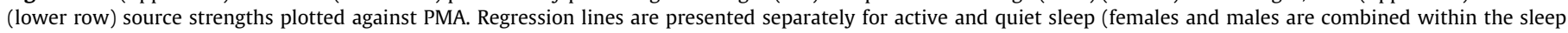
stages). No significant correlations existed. Note also that the absence of M200 in AS (strength zero) was not dependent on PMA.

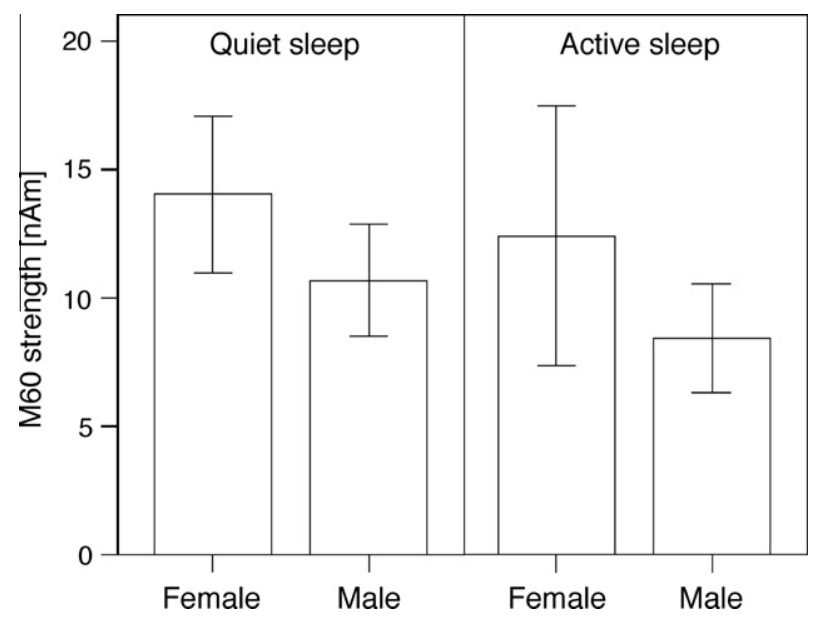

Fig. 4. Source strengths in females and males in quiet sleep (left) and active sleep (right) with error bars indicating 95\% confidence intervals. There were no significant differences between the genders.

sitivity, and positive and negative predictive values vary. This is at least partly explained by between studies differences in patient inclusion criteria, outcome measures, measurement settings, timing of SEP assessment, and criteria of SEP abnormality. Furthermore, many of the above mentioned studies applied recording setting (stimulation frequency and band pass filtering) now considered suboptimal for testing newborns (Vanhatalo and Lauronen, 2006).

The N1 SEP reflects intactness of the somatosensory pathways from the periphery to the SI, but is of limited value in evaluating intracortical processing. Our SEF method adds to the widely available SEP techniques by allowing evaluation of activity not only from SI but also from SII. From a basic physiologic perspective SII plays a role in e.g. tactile learning (Ridley and Ettlinger, 1978), haptic size and shape perception (Hsiao, 2008), bimanual integration (Simões and Hari, 1999), and integration of sensory and motor information (Huttunen et al., 1996). In adults, SII lesions cause tactile agnosia (Caselli, 1993). However, SII lesions in newborns may not manifest themselves in exactly similar ways as those in adults as during early development the brain has remarkable plastic potential to compensate for brain damage (for a review see e.g. Staudt, 2010). For example, in macaques, adults develop severe impairment of texture and shape perception after SII lesions (Ridley and Ettlinger, 1978), whereas infants only display a moderate and temporary deficit in such texture tasks (Carlson and Burton, 1988).

Only few clinically oriented adult MEG studies have concentrated on the SII responses, probably due to the dependence of these responses on e.g. attention and vigilance state (Kitamura et al., 1996; Kakigi et al., 2003) whereby SII responses are not always detectable even in normal adults (e.g. Wikström et al., 1997). Recently, however, Forss and colleagues (2011) reported in adult stroke patients that whereas SI responses to index finger stimulation did not correlate with hand motor function or its recovery, amplitudes of SEFs from the contralateral parietal operculum (near or at SII) did. The weaker the parietal opercular source strength, the clumsier the hand's function was (Forss et al., 2011). In our healthy newborns, the SII activity was clear in more than $90 \%$ of cases in QS and, particularly, none of the newborns with recordings from both hemispheres displayed SII activity on one side only. Previously, a preliminary study in very preterm infants 
measured at term age noted some correlation between absence of SII activity in QS and brain pathology identified from structural MRIs (Nevalainen et al., 2008b). Given this and the high prevalence of SII responses during QS in our healthy newborns, the lacking SII activity in QS is apparently an attractive candidate to be tested for prognostic implications also in newborns.

In clinical settings, individual interhemispheric differences may aid in discovering unilateral brain pathology. Our data from eight healthy newborns during QS showed no significant differences in SI or SII SEFs between the hemispheres at group level, and also at individual level the time course of activity of the SI and SII sources was remarkably similar. In healthy adults, the group level results of interhemispheric comparisons are somewhat contradictory: some suggest the SI sources in the right hemisphere to be located more laterally than in the left hemisphere (MEG: Wikström et al., 1997; EEG: Jung et al., 2003, 2008; Sutherland and Tang, 2006), but others found no differences in source locations between hemispheres (MEG: Rossini et al., 1994; Tecchio et al., 1997). Furthermore, stronger SI source strengths (MEG: Rossini et al., 1994; EEG: Jung et al., 2003, 2008) have been reported in the left than right hemisphere, but these findings were not corroborated by others (MEG: Tecchio et al., 1997; Wikström et al., 1997). At an individual level, in adult stroke patients, initially large interhemispheric differences in latency of SI SEFs were associated with worse functional recovery (Gallien et al., 2003). Regarding the SII, in adults, some studies suggest stronger responses in the left than right hemisphere (MEG: Forss et al., 1994; Simões et al., 2002; EEG: Jung et al., 2009). Others, however, found no significant interhemispheric differences in SII source strength in adults (Wikström et al., 1997) which was also the case with our newborns.

Finally, our results indicate that in fullterm newborns, studied during the neonatal period, PMA, height, or gender exhibit no significant effects on peak latency or strength of the M60 or M200 tactile SEFs. An earlier newborn SEP study noted no gender differences in the latency of the earliest cortical response to electric stimulation of median nerve, $\mathrm{N} 1$ at around $30 \mathrm{~ms}$, either (Lafrenière et al., 1990), whereas no previous reports on effects on response amplitudes exist. On the contrary, in another SEP study, the latency of the N1 to median nerve stimulation was significantly shortened with increasing PMA from 36.5 to 43 weeks (Gibson et al., 1992). In addition, during the same period, the SEP waveform changed from a simple negative deflection towards a more complex multipeak pattern (Gibson et al., 1992). However, with our tactile stimulation protocol the $30 \mathrm{~ms}$ peak corresponding to N1 SEP is not usually distinguishable from the broader M60, which did not exhibit any latency effects. Furthermore, no clear changes existed in source activity patterns to tactile stimulation with increasing PMA.

As a technical note, the evoked responses in infant (and adult) MEG studies are affected by movements of the head with respect to the MEG device. In infants, the disproportion between the head and the measuring device further emphasizes the head movement issue. We dealt with this problem by conducting the recordings when the infants were asleep and lying still. One or two researchers were constantly observing the infant and when occasional twitches occurred and the head moved, the MEG recording was interrupted and the head position measurement was repeated. As the SI and SII responses are reliably recorded during quiet sleep in particular, conducting somatosensory MEG studies in infants during sleep will be method of choice in the future as well. In addition, continuously measuring the head position may facilitate the infant measurements as at least part of the head movements can be compensated without interrupting the recording.

MEG consistently detects activity from the primary and secondary somatosensory areas in healthy fullterm newborns after tactile stimulation of the index finger during quiet sleep. Thus, a multichannel recording and source analysis approach clearly add to the traditional SEP methods, that concentrate on the earliest cortical responses, by enabling studying higher level somatosensory processing also in clinical populations. In clinical settings, as long as the somatosensory evoked fields are recorded within the neonatal period (PMA 37-44 weeks), no corrections for height, PMA, or gender are necessary for interpreting the results but, importantly, the evaluation should be conducted from quiet sleep data.

\section{Acknowledgements}

We are grateful to all our participants and their families for preparing the way for this study. We thank the personnel of the maternity ward of the Department of Obstetrics and Gynaecology at the Helsinki University Central Hospital for seamless co-operation. We also thank M.Sc. Jussi Nurminen for technical advice. The study was financially supported by The Maud Kuistila Memorial Foundation, The Emil Aaltonen Foundation, the Jenny and Antti Wihuri Foundation, the Helsinki University Central Hospital Research Grants, and the aivoAALTO project of the Aalto University.

\section{References}

Arichi T, Moraux A, Melendez A, Doria V, Groppo M, Merchant N, et al. Somatosensory cortical activation identified by functional MRI in preterm and term infants. Neuroimage 2010;49:2063-71.

Carlson M, Burton $\mathrm{H}$. Recovery of tactile function after damage to primary or secondary somatic sensory cortex in infant Macaca mulatta. J Neurosci 1988;8:833-59.

Caselli RJ. Ventrolateral and dorsomedial somatosensory association cortex damage produces distinct somesthetic syndromes in humans. Neurology 1993;43:762-71.

Desmedt JE, Brunko E, Debecker J. Maturation of the somatosensory evoked potentials in normal infants and children, with special reference to the early N1 component. Electroencephalogr Clin Neurophysiol 1976;40:43-58.

Erberich SG, Panigrahy A, Friedlich P, Seri I, Nelson MD, Gilles F. Somatosensory lateralization in the newborn brain. Neuroimage 2006;29:155-61.

Forss N, Hari R, Salmelin R, Ahonen A, Hämälainen M, Kajola M, et al. Activation of the human posterior parietal cortex by median nerve stimulation. Exp Brain Res 1994;99:309-15.

Forss N, Mustanoja S, Roiha K, Kirveskari E, Mäkelä JP, Salonen O, et al. Activation in parietal operculum parallels motor recovery in stroke. Hum Brain Mapp 2011. http://dx.doi.org/10.1002/hbm.21230.

Gallien P, Aghulon C, Durufle A, Petrilli S, de Crouy AC, Carsin M, et al. Magnetoencephalography in stroke: a 1-year follow-up study. Eur J Neurol 2003;10:373-82.

George SR, Taylor MJ. Somatosensory evoked potentials in neonates and infants: developmental and normative data. Electroencephalogr Clin Neurophysiol 1991;80:94-102.

Gibson NA, Brezinova V, Levene MI. Somatosensory evoked potentials in the term newborn. Electroencephalogr Clin Neurophysiol 1992;84:26-31.

Heep A, Scheef L, Jankowski J, Born M, Zimmermann N, Sival D, et al. Functional magnetic resonance imaging of the sensorimotor system in preterm infants. Pediatrics 2009;123:294-300.

Hrbek A, Karlberg P, Olsson T. Development of visual and somatosensory evoked responses in pre-term newborn infants. Electroencephalogr Clin Neurophysiol 1973;34:225-32.

Hsiao S. Central mechanisms of tactile shape perception. Curr Opin Neurobiol 2008; $18: 418-24$.

Huttunen J, Wikström H, Korvenoja A, Seppäläinen AM, Aronen H, Ilmoniemi RJ Significance of the second somatosensory cortex in sensorimotor integration: enhancement of sensory responses during finger movements. Neuroreport 1996;7:1009-12.

Jung P, Baumgärtner U, Bauermann T, Magerl W, Gawehn J, Stoeter P, et al. Asymmetry in the human primary somatosensory cortex and handedness. Neuroimage 2003;19:913-23.

Jung P, Baumgärtner U, Magerl W, Treede RD. Hemispheric asymmetry of hand representation in human primary somatosensory cortex and handedness. Clin Neurophysiol 2008;119:2579-86.

Jung P, Baumgärtner U, Stoeter P, Treede RD. Structural and functional asymmetry in the human parietal opercular cortex. J Neurophysiol 2009;101:3246-57.

Kakigi R, Naka D, Okusa T, Wang X, Inui K, Qiu Y, et al. Sensory perception during sleep in humans: a magnetoencephalograhic study. Sleep Med 2003:4:493-507.

Kitamura Y, Kakigi R, Hoshiyama M, Koyama S, Nakamura A. Effects of sleep on somatosensory evoked responses in human: a magnetoencephalographic study. Brain Res Cogn Brain Res 1996;4:275-9.

Klimach VJ, Cooke RW. Short-latency cortical somatosensory evoked responses of preterm infants with ultrasound abnormality of the brain. Dev Med Child Neurol 1988;30:215-21. 
Lafrenière L, Laureau E, Vanasse M, Forest L, Ptito M. Maturation of short latency somatosensory evoked potentials by median nerve stimulation: a crosssectional study in a large group of children. Electroencephalogr Clin Neurophysiol Suppl 1990;41:236-42.

Laureau E, Majnemer A, Rosenblatt B, Riley P. A longitudinal study of short latency somatosensory evoked responses in healthy newborns and infants. Electroencephalogr Clin Neurophysiol 1988;71:100-8

Lauronen L, Nevalainen P, Wikström H, Parkkonen L, Okada Y, Pihko E. Immaturity of somatosensory cortical processing in human newborns. Neuroimage 2006;33:195-203.

Majnemer A, Rosenblatt B, Riley PS. Prognostic significance of multimodality evoked response testing in high-risk newborns. Pediatr Neurol 1990;6:367-74.

Majnemer A, Rosenblatt B. Evoked potentials as predictors of outcome in neonatal intensive care unit survivors: review of the literature. Pediatr Neurol 1996;14:189-95.

Mathur AM, Neil JJ, Inder TE. Understanding brain injury and neurodevelopmental disabilities in the preterm infant: the evolving role of advanced magnetic resonance imaging. Semin Perinatol 2010;34:57-66.

Medvedovsky M, Taulu S, Bikmullina R, Ahonen A, Paetau R. Fine tuning the correlation limit of spatio-temporal signal space separation for magnetoencephalography. J Neurosci Methods 2009;177:203-11.

Nevalainen P, Lauronen L, Sambeth A, Wikström H, Okada Y, Pihko E. Somatosensory evoked magnetic fields from the primary and secondary somatosensory cortices in healthy newborns. Neuroimage 2008a;40:738-45.

Nevalainen P, Pihko E, Metsäranta M, Andersson S, Autti T, Lauronen L. Does very premature birth affect the functioning of the somatosensory cortex? - A magnetoencephalography study. Int J Psychophysiol 2008b;68:85-93.

Pierrat V, Eken P, Truffert P, Duquennoy C, de Vries LS. Somatosensory evoked potentials in preterm infants with intrauterine growth retardation. Early Hum Dev 1996;44:17-25.

Pierrat V, Eken P, de Vries LS. The predictive value of cranial ultrasound and of somatosensory evoked potentials after nerve stimulation for adverse neurological outcome in preterm infants. Dev Med Child Neurol 1997;39:398-403.

Pihko E, Lauronen L, Wikström H, Taulu S, Nurminen J, Kivitie-Kallio S, et al Somatosensory evoked potentials and magnetic fields elicited by tactile stimulation of the hand during active and quiet sleep in newborns. Clin Neurophysiol 2004;115:448-55.

Pihko E, Lauronen L, Wikström H, Parkkonen L, Okada Y. Somatosensory evoked magnetic fields to median nerve stimulation in newborns. Int Congr Ser 2005;1278:211-4

Pihko E, Nevalainen P, Stephen J, Okada Y, Lauronen L. Maturation of somatosensory cortical processing from birth to adulthood revealed by magnetoencephalography. Clin Neurophysiol 2009;120:1552-61.

Pihko E, Lauronen L, Kivistö K, Nevalainen P. Increasing the efficiency of neonatal MEG measurements by alternating auditory and tactile stimulation. Clin Neurophysiol 2011;122:808-14.

Pike AA, Marlow N. The role of cortical evoked responses in predicting neuromotor outcome in very preterm infants. Early Hum Dev 2000;57:123-35.

Prechtl HF. The behavioural states of the newborn infant (a review). Brain Res 1974;76:185-212.
Ridley RM, Ettlinger G. Further evidence of impaired tactile learning after removals of the second somatic sensory projection cortex (SII) in the monkey. Exp Brain Res 1978;31:475-88.

Rossini PM, Narici L, Martino G, Pasquarelli A, Peresson M, Pizzella V, et al. Analysis of interhemispheric asymmetries of somatosensory evoked magnetic fields to right and left median nerve stimulation. Electroencephalogr Clin Neurophysiol 1994;91:476-82.

Seppä M. Voxlab. A visualization tool for multi-modal inter-subjectneuroimaging. In: Program No. 625.24/ZZ71. 2011 Neuroscience Meeting Planner, Washington, DC: Society for Neuroscience, 2011.

Simões C, Hari R. Relationship between responses to contra- and ipsilateral stimuli in the human second somatosensory cortex SII. Neuroimage 1999;10:408-16.

Simões C, Alary F, Forss N, Hari R. Left-hemisphere-dominant SII activation after bilateral median nerve stimulation. Neuroimage 2002;15:686-90.

Sutherland MT, Tang AC. Reliable detection of bilateral activation in human primary somatosensory cortex by unilateral median nerve stimulation. Neuroimage 2006;33:1042-54

Smit BJ, Ongerboer de Visser BW, de Vries LS, Dekker FW, Kok JH. Somatosensory evoked potentials in very preterm infants. Clin Neurophysiol 2000;111:901-8.

Staudt M. Brain plasticity following early life brain injury: insights from neuroimaging. Semin Perinatol 2010;34:87-92.

Taulu S, Simola J. Spatiotemporal signal space separation method for rejecting nearby interference in MEG measurements. Phys Med Biol 2006;51:1759-68.

Tecchio F, Rossini PM, Pizzella V, Cassetta E, Romani GL. Spatial properties and interhemispheric differences of the sensory hand cortical representation: a neuromagnetic study. Brain Res 1997:767:100-8.

Trollmann R, Nüsken E, Wenzel D. Neonatal somatosensory evoked potentials: maturational aspects and prognostic value. Pediatr Neurol 2010;42:427-33.

Vanhatalo S, Lauronen L. Neonatal SEP - back to bedside with basic science. Semin Fetal Neonatal Med 2006;11:464-70.

Vanhatalo S, Jousmäki V, Andesson S, Metsäranta M. An easy and practical method for routine, bedside testing of somatosensory systems in extremely low birth weight infants. Pediatr Res 2009;66:710-3.

White CP, Cooke RW. Somatosensory evoked potentials following posterior tibial nerve stimulation predict later motor outcome. Dev Med Child Neurol 1994;36:34-40.

Wikström H, Roine RO, Salonen O, Aronen HJ, Virtanen J, Ilmoniemi RJ, et al. Somatosensory evoked magnetic fields to median nerve stimulation: interhemispheric differences in a normal population. Electroencephalogr Clin Neurophysiol 1997;104:480-7.

Willis J, Seales D, Frazier E. Short latency somatosensory evoked potentials in infants. Electroencephalogr Clin Neurophysiol 1984;59:366-73.

Willis J, Duncan MC, Bell R, Pappas F, Moniz M. Somatosensory evoked potentials predict neuromotor outcome after periventricular hemorrhage. Dev Med Child Neurol 1989;31:435-9.

Woodward LJ, Anderson PJ, Austin NC, Howard K, Inder TE. Neonatal MRI to predict neurodevelopmental outcomes in preterm infants. $\mathrm{N}$ Engl J Med 2006;355:685-94.

Zhu Y, Georgesco M, Cadilhac J. Normal latency values of early cortical somatosensory evoked potentials in children. Electroencephalogr Clin Neurophysiol 1987;68:471-4. 